reality of the colony as a ground for conflict as well as cooperation makes for complexity, but Seeley inadvertently gives his readers optimism for the future.

Ross H. Crozier is at the School of Genetics and Human Variation, La Trobe University, Bundoora, Victoria 3083, Australia.

\section{The ants revisited}

\author{
Jürgen Heinze
}

Social Evolution in Ants. By Andrew F. G. Bourke and Nigel R. Franks. Princeton University Press: 1995. Pp. 529. £55, $\$ 75$ (hbk); £19.95, \$29.95 (pbk).

The Earth Dwellers: Adventures in the Land of the Ants. By Erich Hoyt. Simon and Schuster: 1996. Pp. 319. \$24.

ANTS grow fungi on chewed-up leaves, tend herds of aphids, engage in territorial wars, and may ruin a picnic almost everywhere. Their fascinating evolutionary success is thought to be largely caused by eusociality: ants live in colonies consisting of one or several reproductive members, the queens, and a much larger number of typically nonreproductive workers. Because of the apparent altruism of the worker caste and the diversity of colony organization, ants have become model organisms in the study of social evolution. A few years ago, Bert Hölldobler and E. O. Wilson delivered a comprehensive account of the behaviour and the evolution of ants in the Pulitzerprizewinning monograph The Ants, praised both for its scientific rigour and for its artistic presentation. One might wonder, therefore, whether there is much room for another ant book.

But Social Evolution in Ants by Andrew Bourke and Nigel Franks fills a gap opened earlier this decade. Ant colonies are often believed to function smoothly and without friction among their members. Yet kin-selection theory predicts that the interests of nest-mates eventually diverge. Recent studies have indeed shown that conflicts of interest may strongly shape the pattern of reproduction and the social organization of ant colonies. Bourke and Franks illustrate these and other new aspects of ant life with extraordinary clarity and precision.

Each of the 12 chapters is organized in easy-to-read subunits and ends with a conclusion and a summary. Boxes provide supplementary information about central topics discussed in the text, such as the exact meaning of 'relatedness' and the mechanism of sex determination, or simple calculations to prove central statements. The authors lay much emphasis on a lucid presentation and critical examination of kin-selection

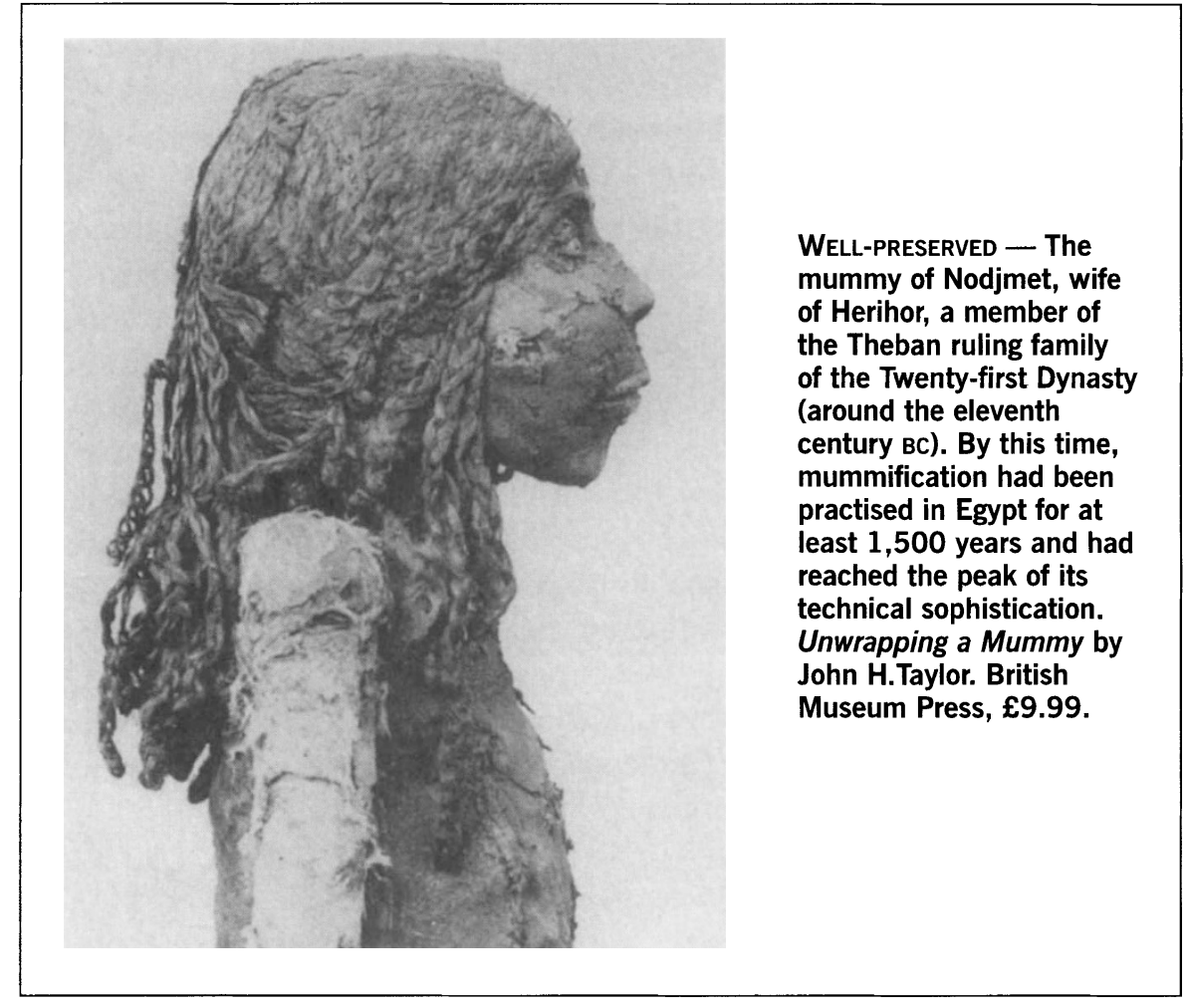

theory and rival hypotheses for the evolution of social behaviour. In so preparing the way for models devised to explain the origin of 'altruistic' workers and the details of intracolonial conflict, they provide a stringent, gene-centred analysis of how selection works, which extends much beyond ants and will be helpful to all wishing to understand social evolution.

Because of haplodiploid sex determination, workers in an ant colony with a single, once-mated queen are more closely related to their sisters than to their brothers, whereas the queen is equally related to both her sons and her daughters. Workers and queens therefore favour different sex-investment ratios. This conflict is additionally complicated by how often the queen mates and the number of queens in a colony. Starting with R. A. Fisher's fundamental model of why equal investment in the sexes is typically evolutionarily stable in diploid organisms, Bourke and Franks elegantly derive sex-ratio theory in ants and provide an excellent overview of recent experimental tests that indicate that workers indeed respond to changed relatedness asymmetries in a colony and manipulate sex investment. Further conflicts arise when workers can produce their own sons from unfertilized eggs or when there are many queens in the same colony. Ritualized or overtly aggressive interactions among nest-mates may then lead to the formation of social hierarchies in which only one or two top-ranking individuals reproduce. The authors review the theory underlying these conflicts and empirical studies, and explain how ecological parameters and the genetic structure of the colony determine how strongly reproduction is skewed.

Also covered are the fascinating diversity of reproductive strategies, which the authors examine in the light of lifehistory theory, as well as the division of labour in ants. Here they compare various models such as age polyethism (where division of labour depends on age) with an alternative - or at least supplementary - model, 'foraging for work', where task allocation is more-orless self-organized.

As a comprehensive review of recent trends in evolutionary biology in ants, Social Evolution in Ants is recommended not only to people enthusiastic about social insects but also to those with a broad interest in evolution in general. The Earth Dwellers by Erich Hoyt, by contrast, is a mixture of ant stories, scientific information and anecdotes about ant sionally find it difficult to distinguish fact from fancy. Do ants really feel fear and hear airborne sound? Or do they really engage in slave-raids? With much of the book based on interviews with Wilson, it reads like a second-hand account of information that can be found at firsthand in Wilson's autobiography The Naturalist (Island/Viking, 1994) and Hölldobler and Wilson's Journey to the Ants (Harvard University Press, 1994). $\square$

Jürgen Heinze is in the Lehrstruhl Verhaltens-physiologie und Soziobiologie, Theodor-Boveri-Institut (Biozentrum), Am Hubland, D-97074 Würzburg, Germany. researchers. The naive reader may occa- 